Brit. J. Psychiat. (1984), 144, 437-443

\title{
Correspondence
}

Correspondents should note that space is limited and shorter letters have a greater chance of publication. The Editors reserve the right to cut letters and also to eliminate multitudinous references. Please try to be concise, strictly relevant and interesting to the reader, and check the accuracy of all references in Journal style.

\section{TREATMENT OF NEUROLEPTIC MALIGNANT SYNDROME}

DeAr Sir,

Dr Scott (Journal, January 1984, 143, 98) drew attention to treatment of the neuroleptic malignant syndrome (NMS) with dantrolene sodium, a peripheral muscle relaxant. There is another and perhaps more pharmacologically logical treatment available. Indirect evidence is available that NMS is caused by a relative postsynaptic receptor dopamine depletion (White, 1983). Bromocriptine, a postsynaptic dopamine agonist, has been used successfully as a treatment in NMS (Mueller et al, 1983).

There have been two other recent reports of the use of bromocriptine. Zubenko and Pope (1983) successfully used $30 \mathrm{mg}$ per day on a patient who had been on depot fluphenazine decanoate and lithium. A significant response was noted within six hours, blood pressure and temperature were normal within three days. A relapse occurred within five days of reducing the dose to $5 \mathrm{mg}$ per day. An increase of dose resulted in "a rapid remission".

Interestingly, Granato et al (1983) used both dantrolene sodium and bromocriptine. The patient had been receiving fluphenazine decanoate and benztropine. They found that intravenous dantrolene sodium ( $0.8 \mathrm{mg}$ per kilogram body weight) every six hours abolished the fever and made the creatine phosphokinase level normal. However, rigidity, tremulousness and obtundation remained. Amantadine in a dose of $300 \mathrm{mg}$ per day had no effect, but bromocriptine, at a maximal dose of $60 \mathrm{mg}$ per day, was associated with a marked improvement in muscle tone and tremor, within two days.

It therefore seems likely that both bromocriptine and dantrolene sodium may have a place in the specific treatment of the NMS. The problem of future relapse of psychosis remains. If the use of neuroleptics is unavoidable, first attempts could include use of a less potent dopamine antagonist and avoidance of depot preparations. Use of the original neuroleptic introduced gradually in small doses is more controverșial.
Use of oral dantrolene sodium as prophylaxis with a neuroleptic has not been reported and could be contemplated. Bromocriptine as prophylaxis may be similarly considered, if one accepts the doubt that the antipsychotic effect of neuroleptics is mediated via central dopamine receptor blockade (Marsden and Jenner, 1980) although the present evidence is to the contrary (Crow, 1980).

King's College Hospital,

P. D. WHITE

Denmark Hill,

Camberwell,

London SES 9RS

\section{References}

Crow, T. J. (1980) Molecular pathology of schizophrenia: more than one disease process? British Medical Journal, $280,66-8$.

Granato, J. E., Stern, B. J., Ringel, A., Karim, A. H., Krumholz, A., Coyle, J. \& Adler, S. (1983) Neuroleptic malignant syndrome: successful treatment with dantrolene and bromocriptine. Annals of Neurology, 14, 89-90.

Marsden, C. D. \& Jenner, P. (1980) The pathophysiology of extrapyramidal side-effects of neuroleptic drugs. Psychological Medicine, 10, 55-72.

Mueller, P. S., Vester, J. W. \& Fermaglich, J. (1983) Neuroleptic malignant syndrome: successful treatment with bromocriptine. Journal of the American Medical Association, 249, 386-8.

WHITE, P. D. (1983) Neuroleptic malignant syndrome. British Medical Journal, 287, 561.

ZuBenko, G. \& PoPE, H. G. (1983) Management of a case of neuroleptic malignant syndrome with bromocriptine. American Journal of Psychiatry, 140, 1619-20.

\section{TREMOR OF THE EYELIDS}

DeAr Sir,

I was interested to read the letter from Dr Freed in your correspondence column, on rapid tremor of the eyelids after overdose of fluphenazine (Journal, November $1983,143,525-26)$. 